\title{
Semiotika dalam Lirik Lagu Kun Anta oleh Humood Al-Khuder
}

Dita Permata Yadiyanti

\author{
Universitas Islam Negeri Sunan Kalijaga Yogyakarta \\ ditapermata19640@gmail.com
}

\section{Article History:}

Received: February 2, 2021

Revised: February 25, 2021

Accepted: March 19, 2021

Published: March 20, 2021

\section{https://doi.org/10.36835/a}

\section{l-irfan.v4i1.4331}

\section{Keywords:}

Semiotics, Song Lyrics, Kun

Anta, Humood
Abstract: In this research "Semiotics in Kun Anta's Song Lyrics popularized by Humood Al-Khuder" uses a qualitative method, with a corpus of Arabic song lyrics Kun Anta. The purpose of this research is to find out the form of phrases or sentences that contain semiotic meanings in the song lyrics, and to find out the deeper meanings contained therein.The theory used is Charles Sanders Pierce's semiotic theory in which Pierce categorizes the triangle of meaning theory which consists of three main elements, namely, signs, objects, and interpretants. In this study too, the researcher concluded that the lyrics of the kun anta song have deep meaning from the semiotic aspect so that lessons can be learned from the song lyrics.

Abstrak: Pada Penelitian "Semiotika dalam Lirik Lagu Kun Anta yang dipopulerkan oleh Humood Al-Khuder" ini menggunakan metode kualitatif, dengan korpus lirik lagu Arab Kun Anta. Tujuan penelitian ini diantaranya untuk mengetahui bentuk frasa atau kalimat yang mengandung makna semiotik dalam lirik lagu tersebut, serta untuk mengetahui makna-makna yang lebih dalam yang terkandung didalamnya. Teori yang digunakan yaitu teori semiotika Charles Sanders Pierce yang mana Pierce mengkategorikan teori segitiga makna yang terdiri dari tiga elemen utama yakni, tanda, objek, dan interpretan. Dalam penelitian ini pun, peneliti menyimpulkan bahwa lirik lagu kun anta mempunyai makna yang dalam dari aspek semiotik sehingga dapat diambil hikmah serta pelajaran dari lirik lagu tersebut. 


\section{Pendahuluan}

Perkembangan dunia industri media massa, baik itu yang dimiliki oleh media mainstream, media cetak, media elektronik maupun new media, selalu memiliki kontenkonten menarik untuk disajikan bagi para penikmat media. Dengan adanya berbagai ragam konten, baik itu mengandung hiburan, pendidikan serta informasi yang ada dalam sebuah media adalah bentuk usaha dari media untuk menguasai konsumen atau mengkomersilkan suatu konten yang sudah disajikan agar laku di mayarakat. Namun di balik itu semua, konten-konten tersebut memiliki makna dan ideologi-ideologi tersendiri yang sudah dikemas kemudian disampaikan dan disebarluaskan kepada masyarakat, melalui media-media yang ada.

Dampak globalisasi dan kemajuan teknologi telah menciptakan interkoneksi antar manusia. Hal ini ditandai dengan adanya perubahan gaya hidup, perilaku kritis dan kepekaan tinggi. Pola penciptaan nilai dalam industri kreatif yang meliputi sektor kreasi, produksi, distribusi dan komersialiasi pun berubah. Tingginya kreativitas sumber daya manusia yang ditawarkan industri ini menjadi landasan untuk menuju keadaan yang lebih baik. Teknologi infomasi dan komunikasi yang kian akrab dengan pengguna, semakin mendorong munculnya ragam kreativitas tersebut. Melalui internet, berbagai hal tak terduga memberi harapan-harapan baru yang bahkan tak terpikir sedikitpun di era konvensional.

Semiotik adalah ilmu tentang tanda (sign) dan segala yang berhubungan dengan tanda baik itu cara berfungsinya, hubungan dengan kata lain, pengirimnya, dan penerimaan oleh mereka yang mempergunakannya. ${ }^{1}$ Dan bahasa merupakan suatu sistem lambang berupa bunyi, bersifat arbiter, digunakan suatu masyarakat tutur untuk bekerja sama, berkomunikasi, dan mengidentifikasikan diri. Sebagai sebuah sistem, maka bahasa terbentuk oleh sebuah aturan, kaidah, atau pola-pola tertentu, baik dalam bidang bunyi, tata bentuk kata, maupun tata kalimat. ${ }^{2}$ Oleh sebab itu, keterkaitan bahasa

\footnotetext{
${ }^{1}$ A Sobur, Analisis Teks Media. Pt. Remaja Rosdakarya (2015).

2 Abdul Chaer, Tata Bahasa Praktis Bahasa Indonesia. Rineka Cipta. (t.t.)
} 
amat berpengaruh dalam ruang lingkup masyarakat dan bahasa Arab termasuk bahasa yang banyak diserap dalam bahasa Indonesia.

Berbicara tentang bahasa Arab, dimana akhir-akhir ini tidak sedikit masyarakat Indonesia yang mulai menyukai lagu-lagu Arab, oleh karenanya, banyak para pendengar dan penikmat musik Arab yang ingin mengetahui apa arti atau terjemahan yang dikandung dalam lirik lagu Arab yang mereka dengar. Seperti lagu kun anta yang diciptakan sekaligus dinyanyikan Humood AlKhuder penyanyi asal Kwait. Lagu yang dikemas dengan nuansa pop ini berbeda dengan lagu-lagu bahasa Arab sebelumnya yang beredar di Indonesia. Oleh sebab itu, lagu ini mudah diterima oleh banyak kalangan serta bahasa yang digunakan juga menggunakan bahasa Fushah. Akibat fenomena ini peneliti merasa penting mengkaji lagu ini agar makna yang terkandung didalamnya dapat juga dinikmati oleh orang banyak. Dalam hal ini peneliti juga akan memperhatikan dalam pemilihan kata atau diksi yang tepat.

Isi

\section{Metode Penelitian}

Untuk mengkaji tanda dan makna yang terdapat dalam lagu "Kun Anta", penelitian ini menggunakan model Analisis Semiotik Charles Sanders Pierce. Menurut Charles, makna dibangun dalam teori segitiga makna atau triangel meaning. Elemen utamanya adalah sign, object, dan interpretant. Tanda adalah sesuatu yang berbentuk fisik yang dapat ditangkap oleh panca indra manusia maupun dengan pikiran dan perasaan, sehingga memiliki fungsi sebagai tanda untuk mewakili sesuatu yang lain. Salah satu bentuk tanda adalah kata. Tanda biasanya juga disebut dengan representament. ${ }^{3}$

Charles Sanders Peirce adalah seorang filsuf Amerika yang paling orisinal dan multidimensional.

Peirce mengklasifikasikan hubungan segitiga makna atas beberapa bagian struktur yang masing-masing saling mendukung yang disebut dengan trikotomi, yaitu: Sign, Obyek dan Interpreten.

${ }^{3}$ Iskandar, D. S., \& Lestari, R.. Mitos dalam Jurnalisme. (2016) 
Sign merupakan tanda yang merupakan sesuatu yang dikaitkan pada seseorang dalam beberapa hal atau kapasitas. Tanda menunjuk pada seseorang, yakni menciptakan di benak orang tersebut terhadap suatu tanda yang setara, atau suatu tanda yang lebih berkembang. Dalam trikotomi yang pertama sign terbagi menjadi tiga hal, yaitu:

1) Qualisign, yaitu sesuatu yang mempunyai kualitas untuk menjadi tanda. Ia tidak dapat berfungsi sebagai tanda sampai ia terbentuk sebagai tanda.

2) Sinsign, yaitu sesuatu yang sudah terbentuk dan dapat dianggap sebagai representemen, tetapi belum berfungsi sebagai tanda.

3) Legisign, yaitu sesuatu yang sudah menjadi representemen dan sudah berfungsi sebagai tanda. ${ }^{4}$

Dalam perangkat semiotik Pierce membagi sebuah tanda (sign) pada tiga perangkat, yaitu :

1) Icons (ikon) adalah tanda yang mewakili sumber acuan melalui sebuah bentuk replikasi, simulasi, dan imitasi atau persamaan. Sebuah tanda dirancang untuk mempresentasikan sumber acuan melalui simulasi atau persamaan. ${ }^{5}$

2) Indeexes (indeks) adalah sebuah tanda yang mewakili sumber acuan dengan cara menunjukkan padanya atau mengaitkannya secara eksplisit atau implisit dengan sumber acuan lain. ${ }^{6}$ Adapun indeks terbagi menjadi 3 bagian, yaitu: indeks ruang, indeks temporal, dan indeks persona.

a) Indeks ruang mengacu pada suatu lokasi atau ruang suatu benda, makhluk, dan peristiwa dalam hubungannya dengan pengguna tanda.

b) Indeks persona, indeks ini saling menghubungkan pihak-pihak yang mengambil bagian dalam situasi. Kata ganti orang adalah sebuah contoh dari indeks persona

\footnotetext{
${ }^{4}$ A Sobur, Analisis Teks Media. Pt. Remaja Rosdakarya (2015).

${ }^{5}$ Marcel, D.. Pesan tanda dan Makna. Jalasutra. (2004)

${ }^{6}$ Ibid
} 
c) Indeks temporal, indeks ini saling menghubungkan benda-benda dari segi waktu. Grafik waktu dengan keterangan sebelum dan sesudah merupakan contoh dari indeks temporal.

3) Symbol (simbol) merupakan tanda yang mewakili hal yang paling besar dan diakui bersama.

Interpreten merupakan konsep pemikiran dari orang yang menggunakan tanda dan menurubkannya ke suatu makna tertentu atau makna yang ada dalam benak seseorang tentang obyek yang dirujuk dalam sebuah tanda. Ada tiga tahapan yang berdasarkan hubungan antar interpreten dengan tanda, yaitu:

1) Rheme, yaitu tanda yang tidak benar atau tidak salah seperti hampir semua kata tunggal kecuali ya atau tidak. Rheme merupakan tanda pengganti sederhana. Ia merupakan tanda kemungkinan kualitatif yang menggambarkan semacam kemungkinan obyek.

2) Discent dalam Zaimar dijelaskan bahwa tanda yang mempunyai eksistensi yang aktual. Yaitu tanda yang sesuai dengan kenyataan.

3) Argument adalah tanda yang langsung memberikan alasan tentang sesuatu.

\section{Biografi Humood Al-Khuder}

Humood AlKhudher adalah penyanyi berparas tampan asal Negara Kuwait. Salah satu lagunya yang paling populer ialah Kun Anta (Be Yourself) yang sangat menghipnotis para penikmat lagu. Suara yang merdu tidak kalah dengan penyanyi tampan Zayn Malik dan irama lagunya yang begitu unik, membuat para penggemarnya selalu ingin mendengarkannya. Bahkan di Indonesia, lagu Kun Anta menjadi soundtrack sinetron di salah satu stasiun televisi swasta. Berikut Profil Humood AlKhudher.

Perjalanan Karir Humood AlKhudher yang memiliki nama asli Humood Othman AlKhudher, dalam bahasa Arab حود ختمان الخضر. Humood lahir pada tahun 1989. Dia menghabiskan masa kecilnya di Inggris. Kemudian dia kembali dan menetap di Kuwait tempat dimana ia dilahirkan. Minat dan semangat Humood dalam bidang seni 
telah terlihat sejak usianya masih muda. Humood AlKhudher memulai awal karir musiknya pada usia 10 tahun, yang mana pamannya lah yang membuatnya dirinya bergabung dengan acara koral dan studio rekaman. Ia menyelesaikan kuliah S2 Komunikasi Massa di Universitas Kuwait, namun kecintaannya pada musik membuatnya mengambil keputusan untuk fokus pada bidang seni dan mendirikan perusahaan produksi. Humood mengambil pelajaran di American Berklee College of Music di Boston, Massachusetts di Amerika Serikat. Humood merilis banyak single yang sukses secara komersial di Timur Tengah. Dia tampil sebagai penyanyi muda di "Ummi Filisteen" oleh penyanyi Kuwait dan munsheed Mashari al Aarada. Ayahnya adalah seorang profesor di bidang psikologi. Dan menerima gelar PhD dari Inggris, sebuah tempat dimana dia menghabiskan sebagian besar masa kecilnya. Ibunya adalah wanita yang berpendidikan, ramah orang yang kreatif. ${ }^{7}$

Humood mulai masuk secara resmi di dunia tarik suara pada tahun 2002 salah satu album yang berhasil diciptakannya adalah album "Yaa Raji'iy". Kesuksesannya membuat dia mendapatkan penghargaan besar pada acara "Khawatir" di stasiun TV $\mathrm{MBC}$, dan mendapatkan dua juta penonton untuk videonya di youtube. Ia pun memilih Zain Telecom (salah satu operator seluler di Arab) untuk melakukan kampanye media. Selanjutnya dia merilis album disebut Fekra oleh Salam Productions. Judul lagu "Fekra" digunakan sebagai tema iklan TV untuk Zain Network. Ia juga membawakan sebuah lagu untuk program televisi Khawater. "Keep Me True" yang direkam sebagai video klip di Los Angeles, California, diikuti oleh serangkaian konser di Kuwait dan juga Yordania, Yaman serta konser di Istanbul, London, Chicago, Vancouver. Banyak lagunya digunakan dalam iklan promosi di Kuwait dan Dunia Arab. Pada tahun 2013, ia merilis sebuah lagu amal "Zammilouni" yang bertema tentang korban perang sipil di Suriah. Lagu Humood lainnya digunakan dalam kampanye bertemakan Ramadhan dan amal.

Humood AlKhunder menggebrak dunia musik pada awal tahun 2016 lewat single Kun Anta. Video klip Humood AlKhunder yang sudah ditonton 222.438.826 kali

${ }^{7}$ Rizal.. Fakta Humood Al-Khuder Penyanyi Kun Anta yang Gantengnya gak Ketulungan. IDN Times. (2016, Maret) 
sejak dipublikasikan 2 Februari 2016 lalu dan angka tersebut akan terus bertambah dengan 2,1 juta like, 10,6 juta subscriber dan 96.000 komentar pada akun youtubenya, banyak komentar-komentar positif yang masyarakat tunjukan bahkan masyarakat pun masih mendengarkan lagu tersebut sampai ditahun 2021, dilihat dari berbagai komentar pada videoklipnya masyarakat dipenjuru dunia terkena demam Kun Anta seperti negara Malaysia, London, Italy dan masih banyak negara lainnya termasuk Indonesia

Bahkan di Indonesia penyanyi gambus ikut serta dalam mengcover lagu Kun Anta ini yaitu Nissa Sabyan dan sudah dijadikan kedalam albumnya. Dan banyak penyanyi-penyanyi Indonesia di youtube yang ikut serta dalam mengover lagu Kun Anta dengan view lebih dari 100.000 kali tontonan dan bahkan sudah ada versi bahasa indonesianya

Dapat dilihat dalam video klip Kun Anta terdapat berbagai adegan yang diawali dengan seseorang yang selalu iri kepada kelebihan atau fisik seseorang sehingga terkadang ada orang yang ingin merubah wajah karena mereka tidak percaya diri dengan penampilan mereka dan tidak menerima pemberian dari Allah., seolah semuanya itu bisa dirubah dengan harta, harta bukan lah segalanya, rupa yang sempurna bukan lah segalanya tapi ketika kita memberikan sikap yang baik kepada seseorang maka semua keburukan fisik yang dia sesali itu akan sirna dengan sekejap mata, bukan bagaimana fisiknya tapi bagaimana sikapnya. ${ }^{8}$

Pada 1 Januari 2015 Humood menandatangani kontrak rekaman eksklusif dengan Awakening Records, dan kemudian pada bulan yang sama ia merilis album Aseer Ahsan. Lagu Humood berjudul "Kun Anta” telah melebihi 70 juta penayangan di YouTube dan merupakan penjualan terlaris di Malaysia. ${ }^{9}$

${ }^{8}$ http:// digilib.uinsgd.ac.id/37282/ diakses 22 Februari 2021

${ }_{9}^{9}$ Biografi Humood Khuder. (2018, Januari). Profilbos. 


\section{Lirik Lagu Kun Anta}

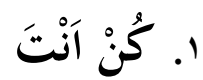

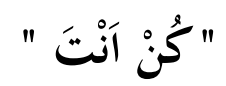

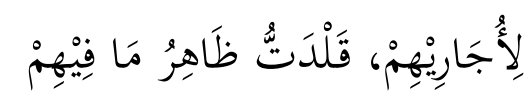

فَبَدَوْتُ شَخْصاً آَخَرْ، كَيْ أَتَفَاخَرْ

وَ ظَنْنتُ أَنَا، أَنِيّ بِذَلِكَكَ حُزْتُ غِنَى

فَوَجَذْتُ أَنِيِ خَاسِرْ فَتِلْكَ مَظَاهرْ

\section{Bagian 1 :}

$$
\begin{aligned}
& \text { لَالَ, لَا نَحْتَاجُ الْمَالَ } \\
& \text { كَيْ نَزْدَادَ جَمَالَا } \\
& \text { جَوْهَرْنًَا هُنَا } \\
& \text { فِيْ القَلْبَ تَكَلَا } \\
& \text { لَالَا نُوْْضِي النَّاسِ بَِّا لَا } \\
& \text { نَرْضَاهُ لَنَا حَالَا , } \\
& \text { ذَاكَ جَمَالنَّا, }
\end{aligned}
$$




$$
\text { يَسْمُوْ يَتَعَالَى }
$$

Oh wo oh........oh wo oooh...

Oh wo oh........oh wo oooh...

كُنْ أَنْتَ تَزْدَدَ جِمَالاً

Oh wo oh.........oh wo oooh...

Oh wo oh........oh wo oooh...

$$
\text { كُنْ أَنْتَ تَزْْدَد مَمَالاً }
$$

La la la la la la la la la la

La la la la la la la la la la

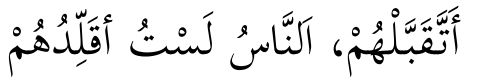

$$
\begin{aligned}
& \text { إلَّال بِمَا يُرْضِينِي، كَيْ أُرْضِيْنِي } \\
& \text { سَأَكُوْنُ أَنَا، مِثْلِيِ تَمَامًا هَذَا أَنَا } \\
& \text { فَفَنَاعَتِي تَكْفِيْنِي، ذَاكَ يَقِيْ }
\end{aligned}
$$

\section{Kembali ke Bagian 1}

$$
\begin{aligned}
& \text { سَأَعُوْنُ أَنَا، مَنْ أَرْضَى أَنَكَ، لَنْ أَسَعْى لَا لِرْضَاهُمْ } \\
& \text { وَأَكُوْنُ أَنَا، مَا أَهْوَى أَنَا، مَالِي وَمَا لِرضَاهُهْم } \\
& \text { سَأَكُوْنُ أَنَا، مَنْ أَرْضَى أَنَكَ، لَنْ أَسَعْى لَا لِرْضَاهُمْ } \\
& \text { وَأَكُوْنُ أَنَا، مَا أَهْوَى أَنَا، مَالِي وَمَا لِرْضَاهُمْ }
\end{aligned}
$$




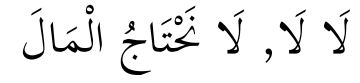

$$
\begin{aligned}
& \text { كَيْ نَزْدَادَ جمَالَا } \\
& \text { جَجْهَرَنْنَ هُنَا } \\
& \text { فِيْ القَلْبِ تَالَالَا } \\
& \text { لَالَا بُنْرضِي النَّاسِ بِمَا لَا } \\
& \text { نَرْضَاهُ لَنَا حَالَا } \\
& \text { ذَاكَ جَمَالنُا, } \\
& \text { يَسْمُوْ يَتَعَالَى }
\end{aligned}
$$

Oh wo oh.........oh wo oooh...

Oh wo oh........oh wo oooh...

$$
\text { كن أنت تزدد جمالاً }
$$

Oh wo oh........oh wo oooh...

Oh wo oh........oh wo oooh... 


\section{Analisis Data}

Berdasarkan lirik lagu diatas, maka peneliti melakukan analisis dengan sistematika sebagai berikut :

\begin{tabular}{|c|c|c|c|c|c|c|}
\hline No & $\begin{array}{l}\text { Lirik Lagu } \\
\text { Kun Anta }\end{array}$ & Makna Leksikal & Ikon & Indeks & Simbol & keterangan \\
\hline 1 & لأجاريهم & Sombong & & $\checkmark$ & & $\begin{array}{l}\text { Indeks } \\
\text { Temporal }\end{array}$ \\
\hline 2 & قلدت & Tidak Percaya Diri & & $\checkmark$ & & $\begin{array}{l}\text { Indeks } \\
\text { Persona }\end{array}$ \\
\hline 3 & ظاهر ما فيهم & Penampilan & & $\checkmark$ & & $\begin{array}{l}\text { Indeks } \\
\text { Persona }\end{array}$ \\
\hline 4 & كن أنت & $\begin{array}{l}\text { Agar Lebih Percaya } \\
\text { Diri }\end{array}$ & & $\checkmark$ & & $\begin{array}{l}\text { Indeks } \\
\text { Persona }\end{array}$ \\
\hline 5 & شخصا اخر & Sifat Pamer & & & $\checkmark$ & Simbol \\
\hline 6 & غنى & Kelebihan & & & $\checkmark$ & Simbol \\
\hline 7 & لا نحتاج المال & Apa Adanya & & $\sqrt{ }$ & & $\begin{array}{l}\text { Indeks } \\
\text { Temporal }\end{array}$ \\
\hline 8 & كي نزداد جمالا & Akhlak yang mulia & & $\checkmark$ & & Indeks Ruang \\
\hline 9 & في القلب تلالا & $\begin{array}{ll}\text { Hati yang } & \\
\text { bergembira }\end{array}$ & & $\sqrt{ }$ & & Indeks Ruang \\
\hline 10 & لالا نرضي & $\begin{array}{l}\text { Ingin menjadi diri } \\
\text { sendiri }\end{array}$ & & $\checkmark$ & & $\begin{array}{l}\text { Indeks } \\
\text { Temporal }\end{array}$ \\
\hline
\end{tabular}

Adapun hasil temuan peneliti pada lirik lagu Kun Anta yang ditinjau dari aspek semiotik, bahwasanya ikon dalam lagu tersebut yaitu Humood Al-khuder, dan juga dapat disimpulkan bahwa, lirik lagu tersebut banyak mengandung unsur indeks temporal dan indeks persona, yang mana isi pesan dari terjemahan lirik lagu tersebut menceritakan tentang seseorang yang awal mulanya tidak percaya atas apa yang ada 
pada dirinya sendiri, karena beberapa alasan yang ia anggap membanggakan dirinya, namun sebetulnya perasaan tersebut hanyalah sebagian dari rasa irinya terhadap orang lain yang lebih baik darinya.

Sebagaimana diketahui bahwa semiotik menurut Saussure merupakan salah satu kajian mengenai tanda-tanda yang ada di kehidupan sosial masyarakat, dan beliau juga yang menyatakan tentang ilmu semiologi.

Selanjutnya, pada terjemahan lirik lagu diatas mengandung makna yang mengajarkan kita bahwasanya memiliki akhlak yang baik tidak hanya diterapkan pada orang lain saja, namun juga harus memperlakukan diri sendiri dengan sebaik mungkin, dengan cara menghiasi diri dengan rasa positif dan kepercayaan pada diri sendiri. Poin ini terletak pada inti dari judul lagu tersebut dengan terjemahan "Jadilah diri sendiri, maka kamu akan menambah kecantikan yang ada". Sebuah inti berupa pesan yang sangat indah dan juga bermakna, membuat para penikmat musik jatuh cinta terhadap lagu Kun Anta yang dipopulerkan oleh Humood Al-Khuder ini.

\section{Penutup}

Berdasarkan hasil temuan penelitian ini dapat disimpulkan bahwa kata maupun kalimat dalam lirik lagu Kun Anta yang dipopulerkan oleh Humood Al-Khuder ini memiliki tanda dan makna-makna semiotik yang bahwasanya kata atau kalimat itu memiliki pesan moral yang dapat diambil dari lagu tersebut. Oleh karena itu, dapat disimpulkan juga bahwa lagu Kun Anta ini bukan hanya sekedar nyanyian atau hiburan semata saja, melainkan juga dapat dipetik hikmah dan pembelajaran dalam lirik lagu tersebut. dan juga merupakan lagu-lagu dapat digunakan untuk menghimbau terciptanya suasana damai. 


\section{Daftar Pustaka}

A Sobur, Analisis Teks Media. Pt. Remaja Rosdakarya (2015).

Abdul Chaer, Tata Bahasa Praktis Bahasa Indonesia. Rineka Cipta. (t.t.)

Iskandar, D. S., \& Lestari, R.. Mitos dalam Jurnalisme. (2016)

Marcel, D.. Pesan tanda dan Makna. Jalasutra. (2004)

Rizal.. Fakta Humood Al-Khuder Penyanyi Kun Anta yang Gantengnya gak Ketulungan. IDN Times. (2016, Maret)

http://digilib.uinsgd.ac.id/37282/

Biografi Humood Khuder. (2018, Januari). Profilbos. 